\title{
Effect of octreotide on gastrointestinal pressure profiles in health and in functional and organic gastrointestinal disorders
}

\author{
K Haruma, J A Wiste, M Camilleri
}

\begin{abstract}
The somatostatin analogue, octreotide, restores normal pressure profiles in disorders of upper gut motility. This study aimed to evaluate the acute effects of octreotide in five healthy subjects and in 50 consecutive patients with functional $(n=22)$ or organic $(n=28)$ dysmotility. Antroduodenojejunal manometry was performed during three hours' fasting, for two hours after a standard meal, and 30 minutes after subcutaneous injection of $50 \mu \mathrm{g}$ octreotide. Antral motility, before and after octreotide, and characteristics of spontaneous migrating motor complexes and octreotide induced activity fronts were compared. Octreotide inhibited antral motility and induced a small intestinal activity front followed by motor quiescence in all healthy subjects and patients. The duration and propagation velocity of activity fronts were greater than those of spontaneous migrating motor complexes. Thirty per cent of activity fronts began simultaneously at different levels of small bowel, and in $20 \%$, a second, normally propagated activity front developed within 30 minutes of octreotide injection. Octreotide induces rapidly propagated, long activity fronts, even in patients with neuropathology, and this may initially facilitate the intestinal propulsion of chyme. Propulsion may not occur, however, if octreotide induces simultaneous activity fronts or if the activity front is followed by prolonged quiescence. Inhibition of antral motility suggests that octreotide may not be effective in gastroparesis.

(Gut 1994; 35: 1064-1069)
\end{abstract}

Upper gastrointestinal manometry is an established method for the identification of stomach and upper small bowel motility disorders. ${ }^{1}$ Studies of pressure profiles in these regions correlate well with two broad categories of motility disorders - neuropathies and myopathies. ${ }^{2}$ Pharmacological studies showing changes in these profiles in health and restoration of normal pressure profiles are usually a prerequisite for developing new treatments for these motility disorders. Thus, several studies have shown that exogenous somatostatin induces a migrating motor complex (MMC)-like activity front in experimental animals and in healthy human volunteers. ${ }^{3-7}$ These observations led to a short study of the clinical efficacy of a long acting somatostatin analogue, octreotide, in patients with progressive systemic sclerosis. Octreotide stimulated MMC-like activity (which will be referred to as an 'activity front' throughout this manuscript) in the small bowel, improved some symptoms, and reduced breath hydrogen excretion after an oral glucose load, suggesting an effect on small bowel bacterial overgrowth. ${ }^{8}$ It is not clear which subsets of patients with progressive systemic sclerosis respond to this medication, but these new and interesting observations suggested that octreotide might restore normal motility in patients with upper gastrointestinal motility disorders.

To further address this hypothesis and to identify which subgroups of patients might respond to octreotide treatment, we evaluated a consecutive series of 50 patients with suspected upper gastrointestinal dysmotility referred to a single clinical motility laboratory. Our primary aims were to evaluate the effects of octreotide on postprandial antral motility and to characterise the duration, amplitude, frequency of contractions, and propagation of the activity front in these patients and in five healthy volunteers. Our secondary aim was to determine from this pilot study whether any specific disease subgroups showed responses that could provide the rationale for further testing in future studies.

\section{Methods}

PATIENTS AND HEALTHY CONTROLS

We studied 50 consecutive patients who were referred for a standard upper gastrointestinal motility study and consented to participate. Patients were 15 to 67 years of age (mean: $37 \cdot 7$ years) and there were 37 women and 13 men. All women of childbearing potential had a negative plasma ( $\beta-\mathrm{HCG})$ pregnancy test within 24 hours of the motility study. Five healthy volunteers (age range: $30-44$ years; mean age: 34.6 years) were recruited by public advertisement. The research protocol was approved by the Mayo Institutional Review Board.

UPPER GASTROINTESTINAL MANOMETRY

This was performed using a multilumen $(n=8$ or 12) assembly with five or six ports placed fluoroscopically across the antroduodenal junction and three or six ports in the duodenum and jejunum. The method has been described fully elsewhere. ${ }^{9}$ Patients stopped taking any medication that might influence 


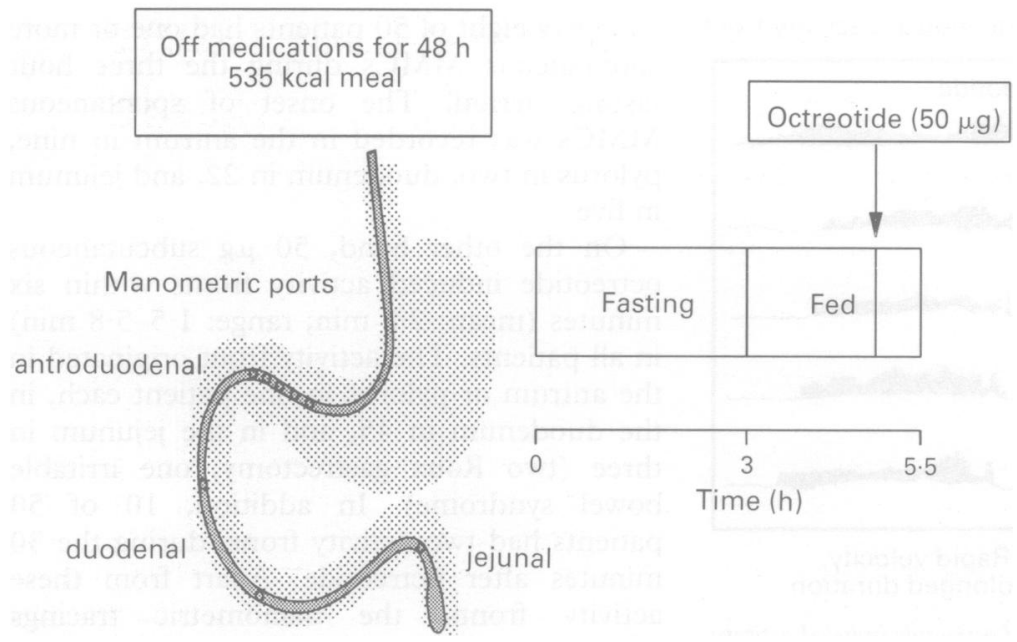

Figure 1: Experimental design the three-hour fasting period, we characterised the first complex. The velocity of propagation was considered fast when the MMC or activity front propagated through the duodenum and jejunum at a rate faster than $11 \mathrm{~cm}$ per minute, which is at the 95th centile for propagation velocities in healthy subjects. ${ }^{10}$

The same parameters were documented for the activity fronts induced by octreotide. The onset of activity fronts at different levels of small intestine was indicated by the time point when that particular level showed a contractile frequency of 10 per min or greater. When the onset of activity fronts at the three or six recording sites in the small bowel were within 10 seconds of the first site they were deemed to be simultaneous. All other fronts were characterised as retrograde or antegrade relative to the site of onset of the octreotide induced activity front. Ten of the 50 patients showed two octreotide induced activity fronts. The characteristics of these second fronts were similarly analysed.

before the study. Pressure profiles were recorded for three hours during fasting and for two hours after a standardised meal. At the end of the latter period, all subjects were given a subcutaneous injection of $50 \mu \mathrm{g}$ octreotide (Sandostatin, Sandoz Pharmaceutical Corp, East Hanover, NJ, USA), and the pressure profile was monitored over the next 30 minutes (Fig 1). A preliminary study in three separate patients had shown that $100 \mu \mathrm{g}$ octreotide invariably induced nausea, and that vomiting occurred within five minutes of the injection in two patients. We had also observed that within five minutes of the subcutaneous injection, a phase III-like activity front was induced in each patient. In view of these preliminary findings, we elected to use a subcutaneous $50 \mu \mathrm{g}$ dose in the subsequent 50 patients. The previous data of Soudah et $a l^{8}$ also suggested that patients with progressive systemic sclerosis were about 10 times less sensitive to the effects of octreotide than healthy subjects, who typically required $10 \mu \mathrm{g}$ of subcutaneous octreotide to induce phase III-like activity fronts.

\section{ANALYSIS OF MANOMETRIC PROFILES}

We quantitated the distal antral motility index for 30 minutes before and after the octreotide injection using the following formula ${ }^{9}$ :

Motility index $=\log _{e}(\Sigma$ amplitudes $\times$ no of contractions +1$)$

Phase III of the fasting MMC was characterised in detail with measurement of mean amplitude, frequency of contractions, site of onset, velocity of propagation, and duration of the complex at the level of the distal duodenum, or in the proximal jejunum for those MMCs with onset beyond the angle of Treitz. In patients with previous Roux-Y gastrectomy, characteristics of the MMC were measured in the Roux limb $10 \mathrm{~cm}$ beyond the gastrojejunostomy. The antral component of the phase III complex was identified by the occurrence of at least five distal antral contractions, followed by prolonged quiescence, indicative of phase I activity, In each subject with more than one spontaneous MMC during

\section{STATISTICAL ANALYSIS}

Student's $t$ test (two-tailed test) was used to compare spontaneous MMCs with octreotide induced activity fronts in healthy subjects and distal antral motility indices before and and patients. Parameters characterising MMCs and first and second octreotide induced activity fronts in the entire group of patients were compared by analysis of variance, followed by Scheffe's F multigroup comparison test. ${ }^{11}$ Data were expressed as mean (SEM).

\section{Results}

QUALITATIVE EFFECTS OF OCTREOTIDE IN HEALTHY SUBJECTS

Manometry showed normal motility in all healthy subjects: all had one or more spontaneous MMC during the three hour fasting period. The onset of the spontaneous MMCs was in the antrum in two subjects and in the duodenum in three. Octreotide $(50 \mu \mathrm{g})$ induced activity fronts within five minutes (mean: $2 \cdot 8$ minutes; range: $1 \cdot 0-4 \cdot 1$ minutes) in all subjects. The activity front originated in the duodenum in all subjects. One volunteer had two activity fronts during the 30 minute period after octreotide.

TABLE I Characteristics of spontaneous migrating motor complexes (MMC) and octreotide induced activity fronts in five healthy volunteers (mean (SEM))

\begin{tabular}{lcl}
\hline & $\begin{array}{l}\text { Spontaneous } \\
M M C\end{array}$ & $\begin{array}{l}\text { Octreotide } \\
\text { induced } \\
\text { activity front }\end{array}$ \\
\hline $\begin{array}{l}\text { Duration (min) } \\
\text { Frequency of contractions }\end{array}$ & $4 \cdot 9(1 \cdot 5)$ & $11 \cdot 8(2 \cdot 7) \dagger$ \\
$\begin{array}{l}\text { (no/min) } \\
\text { Mean amplitude of contractions } \\
\text { (mm Hg) }\end{array}$ & $11 \cdot 6(0 \cdot 3)$ & $11 \cdot 4(0 \cdot 3)$ \\
Propagation velocity (cm/min) & $\begin{array}{r}29 \cdot 1(2 \cdot 0) \\
7 \cdot 6(2 \cdot 0)\end{array}$ & $\begin{array}{l}24 \cdot 1(4 \cdot 1) \\
22 \cdot 4(6 \cdot 1)^{\star} \ddagger\end{array}$ \\
\hline
\end{tabular}

${ }^{\star} p<0.05 ; \mathrm{tp}=0.05 . \ddagger$ Data on propagation excluded from analysis in one patient who had simultaneous activity front. after octreotide treatment in healthy controls 
Spontaneous MMC

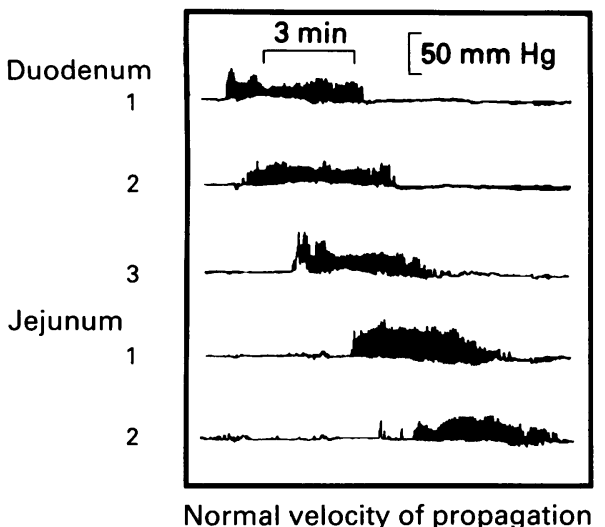

Normal velocity of propagation

Figure 2: Spontaneous migrating motor complexes (MMC) and octreotide induced activity front in a healthy 44 year old male volunteer. Note the rapid velocity of propagation and prolonged duration of the octreotide induced activity front in the right panel. Sensors are all $10 \mathrm{~cm}$ apart.

Octreotide induced activity front

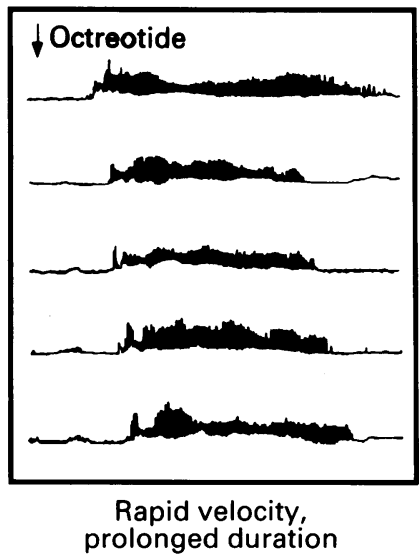

Thirty eight of 50 patients had one or more spontaneous MMCs during the three hour fasting period. The onset of spontaneous MMCs was recorded in the antrum in nine, pylorus in two, duodenum in 22 , and jejunum in five.

On the other hand, $50 \mu \mathrm{g}$ subcutaneous octreotide induced activity fronts within six minutes (mean: $2.8 \mathrm{~min}$; range: $1.5-5.8 \mathrm{~min}$ ) in all patients. The activity front originated in the antrum or pylorus in one patient each, in the duodenum in 45 , and in the jejunum in three (two Roux gastrectomy, one irritable bowel syndrome). In addition, 10 of 50 patients had two activity fronts during the 30 minutes after octreotide. Apart from these activity fronts, the manometric tracings showed motor quiescence or a noticeable paucity of contractions.

In these 50 patients, 34 activity fronts showed propagation (rapid in $32(>11$ $\mathrm{cm} / \mathrm{min})$; normal in two $(<11 \mathrm{~cm} / \mathrm{min}))$; there were 14 simultaneous and one retrograde activity front. The characteristics of propagation could not be evaluated in one patient because its onset was at the most distal sensor in the jejunum. In two patients with Roux-en-Y gastrojejunostomy, spontaneous MMCs were disrupted or poorly formed; octreotide resulted in well propagated activity fronts with normal amplitude and frequency of contractions in the Roux limb (Fig 3). The proportion of propagated octreotide induced activity fronts was similar in the patients with evidence of extrinsic neuropathy (six of eight), functional disease (16 of 22 in functional dyspepsia or irritable bowel syndrome), mechanical obstruction (three of four), or idiopathic gastroparesis (eight of 11).

In the 50 consecutive patients, the clinical diagnosis was irritable bowel syndrome in 17, functional dyspepsia in five, idiopathic gastroparesis in 12, extrinsic neuropathy in eight (three diabetic autonomic neuropathy, four post gastric surgery, and one paraneoplastic syndrome secondary to a small cell lung carcinoma), chronic idiopathic intestinal pseudo-obstruction in three, mechanical obstruction in three, duodenal malrotation in one, and progressive systemic sclerosis in one.

\section{MANOMETRIC STUDIES IN PATIENTS}

Manometric pressure profiles recorded in these patients were classified as follows: normal in 18 patients; postprandial antral hypomotility in 17; features consistent with a neuropathy in 10; mechanical obstruction in four; and features suggestive of a myopathy in one.

TABLE II Effects of octreotide on antral motility in five healthy volunteers (mean (SEM))

\begin{tabular}{|c|c|c|}
\hline & $\begin{array}{l}\text { Before } \\
\text { octreotide }\end{array}$ & $\begin{array}{l}\text { After } \\
\text { octreotide }\end{array}$ \\
\hline $\begin{array}{l}\text { Frequency of contractions } \\
\text { (no } / 30 \mathrm{~min} \text { ) }\end{array}$ & $44 \cdot 6(5 \cdot 7)$ & $11 \cdot 2(3 \cdot 7)^{\star}$ \\
\hline $\begin{array}{l}\text { (mm Hg) } \\
\text { Motility index (mm Hg } 30 \mathrm{~min})\end{array}$ & $\begin{array}{l}44 \cdot 6(5 \cdot 9) \\
11 \cdot 2(0 \cdot 4)\end{array}$ & $\begin{array}{c}35.6(3.2) \\
7.8(0.8) \dagger\end{array}$ \\
\hline
\end{tabular}

\section{COMPARISON OF QUANTITATED MANOMETRIC} PRESSURE ACTIVITIES IN PATIENTS

During the three-hour fasting period, 12 of 50 patients had no spontaneous MMCs, and in five, MMCs started in the jejunum. Motility of the small intestine could not be evaluated in one patient because of technical problems. Thus, 37 spontaneous MMCs were available for the purpose of unpaired statistical comparisons with octreotide induced activity fronts.

We were able to analyse the duration, number of contractions, mean amplitude, and site of origin of activity fronts in all patients. The velocity of propagation was measured in 34 of the 50 patients. Measurements were not possible in the remaining 16 - in one patient, the activity front started at the most distal jejunal sensor, in one the activity front was retrograde, and in 14 activity fronts were simultaneous. Antral motility could not be evaluated in two patients with previous total or subtotal gastrectomy, and in two further patients for technical reasons. In the remaining 46 patients, antral contractions were inhibited completely in eight (Fig 4) and the mean amplitude of contractions after octreotide injection was evaluated in 38 patients.

The duration and propagation velocity of 


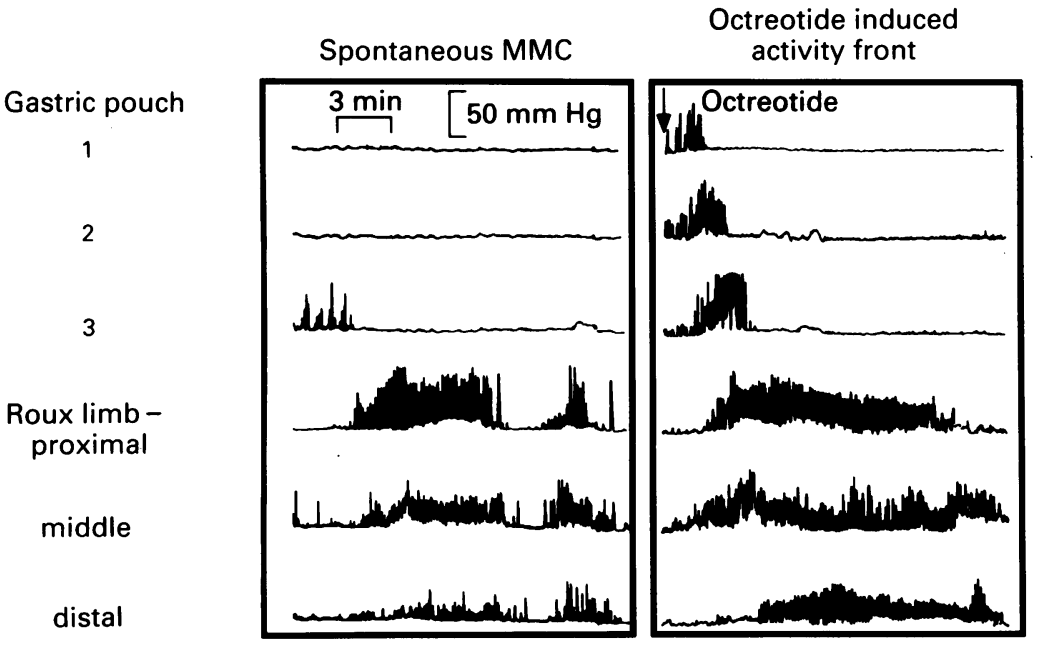

Figure 3: Manometric tracing from a 52 year old women with Roux-en- $Y$ gastrectomy. The fasting tracing (left) shows abnormalities in the propagation of the spontaneous migrating motor complex (MMC). A well propagated activity front occurs after octreotide (right).

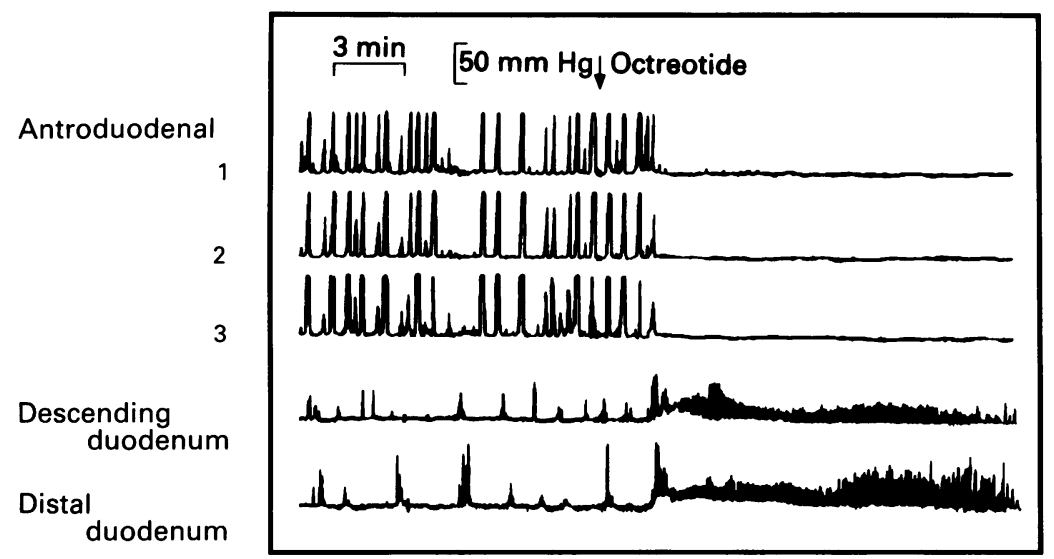

Figure 4: Octreotide induced inhibition of postprandial antral phasic pressure activity and a simultaneous activity front in a 45 year old woman with irritable bowel syndrome.

the first activity fronts were significantly increased compared with spontaneous MMCs. The frequency of contractions and mean amplitude were similar in the two groups (Table III and Fig 2).

Ten patients (20\%) developed a second activity front during the 30 minutes after octreotide (Fig 5). The second activity fronts started in the duodenum from 6.7 to 14 minutes after the first activity front, and the propagation velocity and number of contractions were similar to those observed during spontaneous MMCs, and reduced relative to the first activity fronts. The mean amplitude of contractions of the second activity fronts was decreased relative to both

TABLE III Characteristics of spontaneous migrating motor complexes (MMC) and octreotide induced activity fronts in patients (mean (SEM))

\begin{tabular}{|c|c|c|c|}
\hline & \multirow{2}{*}{$\begin{array}{l}\text { Spontaneous } \\
M M C(n=37)\end{array}$} & \multicolumn{2}{|c|}{ Octreotide induced activity front } \\
\hline & & First $(n=50)$ & Second $(n=10)$ \\
\hline $\begin{array}{l}\text { Duration (min) } \\
\text { Frequency of contractions (no/min) } \\
\text { Mean amplitude of contractions }(\mathrm{mm} \mathrm{Hg}) \\
\text { Propagation velocity }(\mathrm{cm} / \mathrm{min})\end{array}$ & $\begin{array}{r}4 \cdot 8(0 \cdot 4) \\
11 \cdot 7(0 \cdot 2) \\
30 \cdot 2(1 \cdot 5) \\
10 \cdot 2(1 \cdot 0)\end{array}$ & $\begin{array}{l}9 \cdot 0(0 \cdot 7) \\
11 \cdot 7(0 \cdot 2) \\
28 \cdot 2(1 \cdot 3) \\
24 \cdot 9(2 \cdot 9) \ddagger\end{array}$ & $\begin{array}{l}4 \cdot 71(0 \cdot 7) \\
11 \cdot 7(0 \cdot 2) \\
20 \cdot 0(2 \cdot 1) \dagger \\
7 \cdot 85(1 \cdot 1)\end{array}$ \\
\hline
\end{tabular}

${ }^{\star} \mathrm{p}<0.05$ : compared with spontaneous $\mathrm{MMC}$ and second activity front; $t \mathrm{p}<0.05$ : compared

with spontaneous $M M C$ and first activity front. \$Data on propagation excluded from analysis in 16 patients who had simultaneous $(n=14)$
retrograde $(=1)$ activity fronts, or activity front observed only at the most distal site in the jejunum $(n=1)$. spontaneous MMCs and the first activity fronts (Table III and Fig 5).

The frequency of contractions and the motility index of the distal antrum were significantly decreased after octreotide compared with the 30 minutes before injection; however, the mean amplitude of contractions was similar (Table IV). Four patients (two with idiopathic gastroparesis, one with mechanical obstruction, and one with progressive systemic sclerosis) had an increase in antral motility index after octreotide.

\section{ADVERSE EFFECTS}

Octreotide did not cause any adverse effects in the five healthy volunteers. Six of 50 patients developed the following symptoms: vomiting in three, abdominal cramps in one, and epigastric pain in one. Two of the patients (one with vomiting and one with abdominal cramps) complained of similar symptoms during spontaneous MMCs in the fasting period.

\section{Discussion}

Our study shows that $50 \mu \mathrm{g}$ octreotide causes appreciable changes in the pressure profiles of the upper gastrointestinal tract in health and disease. The most consistent findings, which are likely to be physiologically relevant, are the noticeable inhibition of postprandial distal antral motility and the prompt induction of an activity front with similar mean amplitude and frequency of contractions as observed in spontaneous MMCs. The duration and propagation characteristics of the octreotide induced activity front, however, are significantly different from those of the spontaneous MMCs observed in the same individuals. In most patients with irritable bowel syndrome, functional dyspepsia, and chronic idiopathic intestinal pseudo-obstruction, octreotide inhibited antral motility and induced either simultaneous or rapidly propagated activity fronts. In one patient, a retrograde, rapidly propagated activity front was induced. The degree of antral inhibition and the proportion of propagated activity fronts were similar in the diagnostic subgroups in this heterogenous group of 50 patients.

In patients with evidence of an extrinsic neuropathy, such as diabetic autonomic neuropathy, and those with surgical vagotomy and Roux-en-Y gastrojejunostomy in which the Roux jejunal loop is disconnected from the duodenal pacemaker, there was a clear difference between the abnormally developed or propagated spontaneous MMCs and the normal configuration and aboral propagation of the activity front induced by octreotide. The normal direction of propagation and rapid velocity of the intestinal activity front in these patients may provide the basis for propulsion of chyme which is possibly of therapeutic benefit. We had only one patient with systemic sclerosis and hence were unable to assess critically octreotide's potential benefit in myopathic disorders. ${ }^{8}$ 


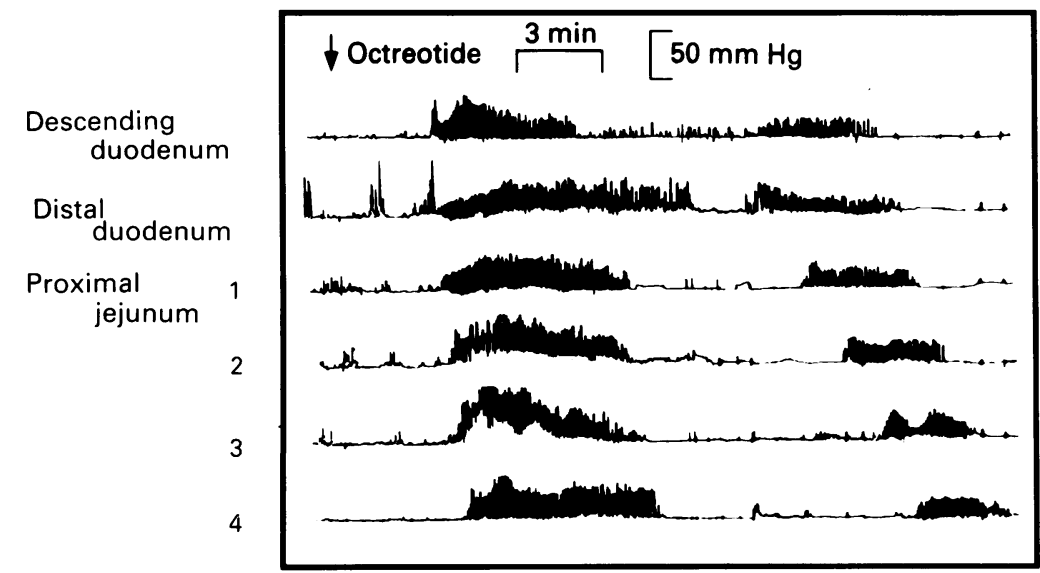

Figure 5: Octreotide induced repeated activity fronts with different propagation velocities in a 30 year old woman with chronic idiopathic intestinal pseudo-obstruction. The propagation of the second activity front is normal. Note the paucity of contractions at all levels between the two activity fronts.

This study provides the first demonstration that octreotide inhibits antral motility, and induces duodenojejunal activity fronts that are characterised by prolonged duration and by a rapid propagation velocity or simultaneous onset at several sites. Previous studies showed that somatostatin induces activity fronts with normal ${ }^{36}$ or slow propagation, ${ }^{78}$ and the duration of the activity front was reported to be similar to that of spontaneous MMCs. The reason for the different results in our studies may be attributed in part to the different experimental design relative to other studies, which were usually performed during fasting, ${ }^{8}$ or to the use of natural forms of somatostatin (somatostatin-14 and -28) rather than octreotide. Soudah et al reported that a smaller dose of subcutaneous octreotide $(10 \mu \mathrm{g})$ decreased the propagation velocity in normal subjects during fasting. ${ }^{8}$ But in their study only two recording sites were located in the small bowel, compared with our studies with four to seven sites in the small intestine, each separated by $10 \mathrm{~cm}$. In a postprandial study of healthy volunteers, Neri et al showed that somatostatin-14 induced activity fronts with normal duration and propagation velocity. ${ }^{6}$ The differences from our observations may reflect the nature of the somatostatin molecule rather than dosages, which are comparable with those used in our studies. It is also important to acknowledge that our study design (three hours' fasting) restricted the ability to define the intrinsically variable properties of the MMC in each individual. More prolonged monitoring might have provided better control data. The duration and propagation velocity of

TABLE IV Effects of octreotide on antral motility in patients

\begin{tabular}{|c|c|c|c|}
\hline & No & $\begin{array}{l}\text { Before } \\
\text { octreotide }\end{array}$ & $\begin{array}{l}\text { After } \\
\text { octreotide }\end{array}$ \\
\hline $\begin{array}{l}\text { Frequency of contractions }(\mathrm{no} / 30 \mathrm{~min}) \\
\text { Mean amplitude of contractions }(\mathrm{mm} \mathrm{Hg}) \\
\text { Motility index }(\mathrm{mm} \mathrm{Hg} 30 \mathrm{~min})\end{array}$ & $\begin{array}{l}46 \dagger \\
38 \ddagger \\
46 \dagger\end{array}$ & $\begin{array}{l}29 \cdot 3(2 \cdot 66) \\
42 \cdot 7(2 \cdot 03) \\
9 \cdot 75(0 \cdot 37)\end{array}$ & $\begin{array}{l}14 \cdot 5(2 \cdot 46)^{\star} \\
40 \cdot 1(3 \cdot 13) \\
7 \cdot 06(0 \cdot 52)^{\star}\end{array}$ \\
\hline
\end{tabular}

octreotide induced activity fronts, however, differed markedly from those of MMC previously reported in prolonged studies performed in laboratory or ambulatory settings. ${ }^{12} 13$ Hence, the overall message would probably have been identical if our fasting observation had been longer.

A second series of activity fronts was observed in 10 patients and one healthy subject during the 30 minutes after octreotide. Interestingly, all of the characteristics of the second activity front except amplitude were similar to those of the spontaneous MMCs. The mechanism resulting in successive activity fronts in these patients, and their different propagation velocity when compared with the first octreotide induced fronts are unclear and deserve further study. From a practical standpoint, it is possible that the second fronts, which are propagated aborally at a normal velocity $(7 \cdot 9(1 \cdot 1) \mathrm{cm} / \mathrm{min})$, may contribute to greater clearance of small bowel contents and may account for the beneficial clinical effects reported in upper gut motility disorders such as systemic sclerosis. ${ }^{8}$

The propulsive capacity of octreotideinduced activity fronts was not investigated in this study. However, the simultaneous or retrograde nature of $15 / 49$ activity fronts would suggest that there would be little antegrade movement of small bowel content during these motor events. Indeed, most of the published reports to date suggest that octreotide retards intestinal transit, since it has been effective in controlling diarrhoea in several patient groups, including carcinoid syndrome, ${ }^{14}$ diabetes mellitus, ${ }^{15}$ ileostomy diarrhoea, ${ }^{16}$ and short gut syndrome. ${ }^{17}$ Octreotide prolongs the mouth to caecum transit time in healthy subjects and in patients with diarrhoea-predominant irritable bowel syndrome, ${ }^{18}$ and scintigraphically measured pyloro-caecal transit of radiolabelled solid residue. ${ }^{19}$ Although, 34 of 49 activity fronts are normally or rapidly propagated, the effects of octreotide in health, functional disease, and organic dysmotilities may not be beneficial because of the prolongation of transit and the general paucity of intestinal contractility after the induction of an activity front.

Our observations in the distal stomach present an unequivocal and significant inhibition of postprandial antral phasic pressure activity. These effects were not previously noted in studies using somatostatin $-14^{6}$ or $28 .^{7}$ Two previous studies suggested that somatostatin inhibits gastric motility in humans. ${ }^{320}$ Thus, Stadaas et al showed that infusion of somatostatin at $0.05 \mathrm{mg} / \mathrm{h}$ and 0.5 $\mathrm{mg} / \mathrm{h}$ significantly reduced gastric motility in response to distention by monitoring contractions by means of a single, flaccid, thin walled bag filled with water. ${ }^{20}$ It is not clear from these studies whether somatostatin affected the fundus or antrum and which molecular form of somatostatin was used. Peeters $\mathrm{et} \mathrm{al}^{3}$ also reported that somatostatin at $1 \cdot 2,2 \cdot 4$, and $4 \cdot 8 \mathrm{pmol} / \mathrm{kg} / \mathrm{min}$ inhibited fasting antral contractile activity which was assessed with a single manometric side hole. 
The effects of somatostatin on postprandial antral motor function have not been previously reported. Our data are supported by the results of gastric emptying studies. Delayed gastric emptying of solid meals ${ }^{2122}$ also suggests that somatostatin inhibits antral motility; conflicting results have been reported regarding the effects of somatostatin on gastric emptying of liquids. ${ }^{21-24}$ Taken together with our observations, these data suggest that octreotide is unlikely to benefit patients with motility disorders affecting the distal stomach, since antral hypomotility is usually associated with impaired gastric emptying of solids. ${ }^{25}$

In summary, our study suggests that octreotide may potentially correct the incoordinated but normal amplitude pressure profiles of patients with extrinsic neuropathies of the small bowel; nevertheless, studies published to date suggest it delays small bowel transit. Moreover, it is unlikely to benefit patients with impaired distal antral motility. Its potential role in functional gastrointestinal disease has recently been studied, and it seems to reduce rectal sensation in health and in patients with irritable bowel syndrome. ${ }^{26} 27$ Our study suggests that patients with extrinsic neuropathy (such as, diabetes, vagotomy) and Roux-en-Y reconstruction after gastric surgery are the most likely to show improvement in patterns of motility. The use of octreotide in patients with upper gastrointestinal motility disorders must await further randomised, placebo-controlled studies of clinical symptoms, small bowel bacterial counts, and physiological effects in well characterised patients with small intestinal myopathies and extrinsic neuropathies.

We thank our colleagues in the Division of Gastroenterology, Mayo Clinic for referring patients for the study, Al Schei and Joe Dahlke for excellent technical support, and Cindy Stanislav for typing and preparing this manuscript.

1 Camilleri M. Study of human gastroduodenojejunal Camilleri M. Study of human gastroduodenojejunal motility: applied physi

2 Colemont LJ, Camilleri M. Chronic intestinal pseudoobstruction: diagnosis and treatment. Mayo Clin Proc 1989; 64: 60-70.

3 Peeters TL, Janssens J, Vantrappen GR. Somatostatin and the interdigestive migrating motor complex in man. Regul Pept 1983; 5: 209-17.

4 Aizawa I, Itoh Z, Harris V, Unger R. Plasma somatostatinlike immunoreactivity during interdigestive period in the dog. F Clin Invest 1981; 68: 206-13.

5 Luz G, Femppel J, Lederer P, Rösch W, Domschke W. Somatostatin induces interdigestive intestinal motor and secretory complex-like activity in man. Gastroenterology 1980; 78: 1212

6 Neri M, Cuccurullo F, Marzio L. Effect of somatostatin on gallbladder volume and small intestinal motor activity in humans. Gastroenterology 1990; 98: 316-21.

7 von der Ohe $M$, Layer P, Wollny C, Ensinck JW, Peeters TL, Beglinger C, Goebell H. Somatostatin 28 and coupling of human interdigestive intestinal motility and pancreatic secretion. Gastroenterology 1992; 103: 974-81.

8 Soudah HC, Hasler WL, Owyang C. Effect of octreotide on intestinal motility and bacterial overgrowth in scleroderma. $N$ Engl f Med 1991; 325: 1461-9.

9 Malagelada J-R, Camilleri M, Staghellini V. Manometric diagnosis of gastrointestinal motility disorders. New York: Thieme Publishers, 1986

10 Rees WDW, Malagelada J-R, Miller LJ, Go VLW. Human interdigestive and postprandial gastrointestinal motor and gastrointestinal hormone patterns. Dig Dis Sci 1982; 27: 321-9.

11 Analysis of variance (ANOVA). Ch 18. In: Statview. Abacus Concepts: Berkeley, CA, 1992: 319-32.

12 Kellow JE, Borody TJ, Phillips SF, Tucker RL, Haddad AC. Human interdigestive motility: variations in patterns from esophagus to colon. Gastroenterology 1986; 91: from esoph

13 Wilson P, Anselmino $M$, Hinder RA, Quigley EMM. Ambulatory antroduodenal manometry in man: development and validation. Gastroenterology 1992; 103: A1402.

14 Kvols LK, Moertel CG, O'Connell MJ, Schutt AJ, Rubin J, Hahn RG. Treatment of the malignant carcinoid syndrome. $N$ Engl f Med 1986; 315: 663-6.

15 Mourad FH, Gorard D, Thillainayagam AV, Colin-Jones D, Farthing MJG. Effective treatment of diabetic diarrhoea with somatostatin analogue, octreotide. Gut 1992; 33: $1578-80$.

16 Williams NS, Cooper JC, Axon ATR, King RFGJ, Baker $M$. Use of a long-acting somatostatin analogue in controlling life threatening ileostomy diarrhoea. BMJ 1984; 289: 1027-8.

17 Nightingale JMD, Walker ER, Burnham WR, Farthing MJG, Lennard-Jones JE. Octreotide (a somatostatin analogue) improves the quality of life in some patients analogue) improves the quality of life in some patients with a short intestine. Alimer

18 O'Donnell LJD, Watsow AJM, Cameron D, Farthing MJG. Effect of octreotide on mouth-to-caecum transit time in healthy subjects in the irritable bowel syndrome. Alimentary Pharmacology and Therapeutics 1990; 4: 177-82.

19 von der Ohe MR, Camilleri M, Thomforde GM. Differential regional effects of octreotide on human gastrointestinal motor function. Gastroenterology 1994 (in press).

20 Stadaas JO, Schrumpf E, Hanssen KF. Somatostatin inhibits gastric motility in response to distention. Scand $\mathcal{f}$ Gastroenterol 1978; 13: 145-8.

21 Petersen JM, Saltzman M, Sherwin RS, Lange R, McCallum RW. Somatostatin inhibits gastric emptying of solids and liquids in man. Dig Dis Sci 1984; 29: A64.

22 Londong W, Angerer M, Kutz K, Landgraf R, Londong V. Diminishing efficacy of octreotide (SMS 201-995) on gastric functions of healthy subjects during one-week administration. Gastroenterology 1989; 96: 713-22.

23 Mogard MH, Maxwell V, Wong H, Reedy TJ, Sytnik B, Walsh JH. Somatostatin may not be a hormonal messenger of fat-induced inhibition of gastric functions. Gastroenterology 1988; 94: 405-8.

24 Long RG, Christofides ND, Fitzpatrick ML, O'Shaughnessy DJ, Bloom SR. Effects of intravenous somatostatin and motilin on the blood glucose and hormonal response to oral glucose. Eur f Clin Invest 1982; 12: monal rest

25 Camilleri M, Brown ML, Malagelada J-R. Relationship between impaired gastric emptying and abnormal gastrointestinal motility Gastroenterology 1986; 91: 94-9.

26 Hasler W, Soudah HC, Owyang C. A somatostatin analogue inhibits afferent pathways mediating perception of rectal distension. Gastroenterology 1993; 104: 1390-7.

27 Hasler W, Soudah H, Owyang C. Somatostatin analog inhibits sensory afferent response to rectal distention in irritable bowel syndrome patients with rectal urgency [Abstract]. Gastroenterology 1992; 102: A457. 